\title{
Impactof Funding On the Adoption of the Third Generation of Delivery in Open and Distance LearningIn Zimbabwe.
}

\author{
Dr O Mafaemail and John Mpofu \\ Zimbabwe Open University
}

\begin{abstract}
The study sought to explore the impact of funding on an open and distance learning (ODL) institution's desire to embrace the Third Generation of delivery of its services and learning materials to students from the perspective of end user practitioners (regional program coordinators and regional IT technicians). A qualitative case study research design was adopted, where purposive sampling was employed to select fifteen regional program coordinators from three of the Zimbabwe Open University's (ZOU) regional centres. Focus Group Discussions (FGDs) were conducted for the generation of data. Data from FGDs were triangulated with interview data from three regional IT technicians. Thematic content analysis was used for data analysis. The process @included transcribing of FGD and interview proceedings, verification, segmenting, coding, enumeration and categorization of coded data into themes and sub-themes. Major findings were that funding adversely impact on ICT infrastructure development, acquisition of computers and related equipment, training of practitioners in IT skills and failure by ODL institutions to pay internet services providers for the bandwidth which meets their requirements. Participants suggested the following strategies in order toameliorate the impact of funding: forging partnership between ODL institutions and private sector, widening student base, engaging the alumni, diversification of programs on offer and universities in a given country like Zimbabwe jointly investing in bringing optic fibre into the country so that they will not be dependent on internet service providers. It was concluded that without adequate funding, adoption of the Third Generation delivery mode by $O D L$ institutions will remain a pipedream. Secondly, the practitioners' awareness of the impact of funding bodes well for health debates as ODL institutions and their stakeholders move towards the Third Generation delivery mode. Recommendations from the study were that $O D L$ institutions need to widen revenue base, fostering partnership between ODL institutions and private sector, fostering of partnership between emerging and well established ODL institutions and collaboration among a country's universities in bringing optic fibre to their doorsteps for increased bandwidth.
\end{abstract}

Key Words:Open and distance learning, funding, third generation and infrastructure.

\section{Introduction}

ODL in Zimbabwe has undergone major transformation in both form and content. Just like any other evolutionary process, it is very hard to definitively identify the end or beginning points of specific stages, as use of older with newer ODL technologies tend to overlap and blur the boundaries. Nonetheless, the main concern has always been the pedagogy used, and not the technology itself per se. As such, one can view the development of ODL in Zimbabwe as simply another 'classic case of necessity,' wherein educators experimented and explored various forms of ICT alone or in convergence with other more established forms of delivery to address pressing societal concerns and achieve academic and institutional goals.

The development of ODL in Zimbabwe has undergone two general stages or generations. At present, ODL is inching towards the third generation which is the focus of this investigation. Unlike other countries, the root of ODL in Zimbabwe was print, mainly being used at a distance. This was the First Generation of delivery. Early ODL in Zimbabwe which were print modules designed, developed, and implemented by the Centre for Distance Education stationed at the University of Zimbabwe consisted of formal courses offered in the area of education and agriculture. Since ZOU is geared towards the Third Generation of delivery, the study sought to provide answers to the following two questions:

- How does funding impact on ODLs' development towards the Third Generation of delivery of learning materials and other related services?

- What strategies can ODL institutions adopt in order to ameliorate the changes emanating from funding in their quest to embrace the Third Generation of delivery? 


\subsection{The delivery mode in ODL \\ II. Review of related Literature \\ In the context of this study, delivery mode refers to the method(s) in which learning materials are presented to students learning through ODL. Passereni and Granger (2000) note that the evolution of ODL has so far seen four generations. Three of these generations are briefly discussed in the Zimbabwean context.}

\subsection{The First Generation of ODL in Zimbabwe}

The First Generation of ODL was characterized mainly by corresponding learning where the student learnt at a distance, mediated by the print media only without any contact with the tutor and with little or no meetings with other students. Chimedza (undated) states that 'The module and possible tutorial letters were the only mode of delivery'. Invariably, the First Generation had implication on the nature of the modules they had to be interactive, having clear learning objectives, learning activities and self-evaluation tests. The modules had to interact with the students since there were no tutors to clarify concepts. Financially, the delivery mode was relatively affordable.

\subsection{Second Generation of ODL delivery}

This is the stage at which the only ODL institution in Zimbabwe is presently at. The Second Generation relies mostly on print-based instructional materials supplemented with occasional face-to-face tutorials facilitated by a university-trained tutor. Lessons are typically contained in a set of print-based learning materials supplemented by face-to-face tutorials. Modules, face-to-face interactions are complemented by audiocassettes, videocassettes and the television (Chimedza, undated). Face-to-face interactions serve as:

- Formally scheduled consultation between the students and the tutors;

- Place for students to undertake various transactions with the university; and

- Opportunities for interaction with fellow ODL students.

In essence, face-to-face tutorials have evolved into an informal system of 'student support,' and not a forum for the actual delivery of instructional content per se. Moreover, these 'tutorials' are never deemed compulsory; it is up to the student to decide for themselves whether to participate or not. Only those students enrolled in Masters programmes are forced by circumstances to attend tutorials because part of their assessment is based on seminar presentations.

The development of knowledge through a combination of face to face and ODL is one of the tactics increasingly adopted in recent times by governments around the world who want to encourage economic development at the local, state and national levels. Howell, Williams \& Lindsay (2003) have shown that distance education programs complemented by face to face learning are growing in importance as centres for the development of knowledge. Zimbabwe has been one of the countries, to develop strategies to encourage this effort aimed at providing people who do not have the opportunity to attend conventional institutions of higher learning (Gwisai, 2006).

The drive towards use of combining face to face and ODL at ZOU in recent years has been commonly employed to resuscitate the efficiency and effectiveness of the institution in helping the students to achieve their full potential in taking degree programs. The implementation of a judicious mix of face-to-face and distance teaching strategy has the capability to demolish the gulf between these modes and to create measurable enhancement in performance. Moreover, a combined teaching strategy has the potential to erode the concept of the inferiority of the distance mode, expand options for the growing population of mature, employed, and offset the substantial cost involved in the preparation of distance packages (Holmberg, 1988).

\subsection{The Third Generation of ODL}

Zimbabwe's only ODL institution has not reached this stage in its delivery of learning materials and other related services. However, preparations for the rolling out of the Third Generation are at an advanced stage. In countries where the Third Generation has been adopted, it has been a convergence of several key factors among them, the growing need for flexible learning, anytime, anywhere, increased availability and access to new ICT and growing demand of geographically dispersed professional groups seeking access to flexible, lifelong learning opportunities. Bates in COL (2004) views the Third Generation as providing learning resources in one or more media and interaction among students as well as between the tutor and students via conferencing technologies (audio, video, computer), email or face-to-face meetings.Passereni and Granger (2000) note that the Third Generation of ODL is characterized by one-way video, two-way audio communication, real time interaction, two-way video conferencing. The system is driven by the following technologies - communication networks (satellites), audio, video, CD-ROMS and bulletin boards.From a Zimbabwean perspective, the Third Generation of ODLshould be viewed as a stage in which Zimbabwean educational providers seek to incorporate ICTs to support their students studying at a distance. 


\subsection{The significance of ICT in ODL}

The Third Generation of delivery in ODL depends on ICT infrastructure to provide effective and efficient services to students. Murali (2009) defines ICT as a group of technologies by which various support services are availed to students at different phases of their learning cycle in ODL. The various phases include the admission phase (program details, fee structure, admission procedure, and registration and re-registration), the learning phase (learning schedule, programme delivery (lectures through video conferencing, webinars, audio and video programmes, multimedia presentations and case studies), evaluation phase (examination schedule, internal and external assessment, examinations, improvement, valuation, revaluation and publication of results and the certification phase (marks/grades updates, certificate printing and issuing and convocation schedule), (Robinson, 2009).

Murali (2008) provides an outline of the prerequisite infrastructure to power ODL institutions into the Third Generation of delivery:

The network infrastructure:-An ODL institution requires a structural network at all its operational nodes (national centre, regional and district centres in the case of the ZOU). The structural network must be interconnected to each other through a well established reliable network so that all student services can be accessed easily by all operational nodes, students and other stakeholders. The network must include adequate and standard network - which are the router, the network switches, the standard network cable (fibre and UTP). Wireless connectivity (Wifi/Wi-max) can also be used.

The computing infrastructure:-The standard computing infrastructure include standard computer hardware such as servers (database servers, web servers, backup/recovery servers and application servers) to host various student learning and support services and personal computers (e.g. desktop computers, laptops, net books) to access and use services.

The stable system and application software:-This is required to develop software for various student learning and support services that are needed at various phases of the student learning cycle. The software is the main component by which an assortment of services can be availed to students and other stakeholders in ODL.

The internet service provider (ISP) and internet bandwidth:-Internet bandwidth is essential for students to access web-based learning and support services. The amount of internet bandwidth (megabytes/second) required is directly proportional to the number of users, who access the services and is one of the parameters to access a service easily in limited time. The accessibility of a service depends on the availability of internet bandwidth reserved in a particular institution where service is hosted. The ISP is an organization that provides internet bandwidth. Zimbabwean examples are Powertel, Econet, Telecel, NetOne and Africom.

The security infrastructure:-This is essential for protection of the systems (servers and personal computers), software, applications and the data that are being used in the institution. The gateway (the starting and ending point of inbound and outbound traffic) of systems must be protected with security devices, which include the firewall, intrusion detection system (IDS), intrusion prevention system (IPS) and antivirus software.

The policy document:-This document covers various policies that are to be enforced in an ODL institution. The policies are broadly categorized as operational, behavioural, resource access (system, service and network), control, security and organizational policies. The policy document may change from time to time due to changing demands, challenges and needs of the ODL institution. The policy document helps an institution to setup the ICT infrastructure properly and to have access control.

Needless to reiterate that ICT infrastructure development demands heavy initial capital investments, this study sought to establish the ODL practitioners' awareness on how funding can impact an institution's aspiration to embrace the Third Generation delivery system. Hopefully such awareness can generate continuous health debates in ODL institutions as they navigate their way to the Third Generation of delivery and beyond.

\section{Research Methodology}

The study adopted a qualitative case study design. Fifteen regional program coordinators were purposively sampled from ZOU's three Matabeleland Regions (Bulawayo, Matabeleland North and South). Focus group discussions were then conducted to generate data. Data from focus group discussions were complemented with interview data from the three IT technicians based in the three regions. Data were analysed using thematic content analysis. The process involved transcribing of focus group discussions and interview 
outcomes, verification of transcribed data through member checking, data segmenting, coding, enumeration and categorizing of data into themes and sub-themes.

\subsection{Composition of Focus Groups \\ Focus Group One}

IV. Findings and Discussions

The group was composed of five members (three females and two males). With the exception of one member who was pursuing a PhD Degree, the rest of the members were holders of Masters Degrees in their respective areas. All the members had more than five years teaching experience in an ODL institution.

\section{Focus Group Two}

The group was composed of five male lecturers, depicting the composition of the teaching staff in the region. Members were relatively new in teaching in an ODL institution as their teaching experiences were between one year and two years. One member held a PhD Degree in Education, while the rest were holders of Masters Degrees in their respective teaching areas.

\section{Focus Group Three}

The group was composed of five male lecturers. Similar to the region where focus group three was drawn, there were no female lecturers in the region where focus group three was drawn. The teaching experience ranged between three years and five years. All the five lecturers were holders of Masters Degrees in their areas of specializations.

\subsection{Biodata of the Three Technicians}

Two of the technicians were male, while one was female. One held a BSc in Computer Science, while the other two had Higher National Diplomas in IT. Their experience of working in an ODL institution IT departments ranged between two and fours.

\subsection{Challenges experienced by ODL institutions due to inadequate funding}

A number of sub-themes emerged under this theme. Presented and discussed below are those which resonated in focus group discussions as well as in-depth interviews. It was generally felt that without adequate funding ODL institutions find it difficult to procure requisite equipment and perform certain activities within the institutions' key result areas.

\subsubsection{Acquisition of Computers, Servers, Uninterrupted Power Suppliers (UPS) and other related equipment}

The Third Generation being Computer driven, most participants felt that without adequate funding, ODL institutions will find it very difficult to acquire computers. In the Third Generation of delivery, computers play a pivotal role in the dissemination and reception of learning materials. Tutors use computers to disseminate the information - likewise students also use computers to access the information, work on their assignments and submit them online. Tutors are also supposed to mark and give students feedback online. In a fully fledged Third Generation institution, most services - ranging from advertisement of courses on offer, applications, registration, library facilities, examination timetables and notification of results are done. All these activities require computers and other related equipment. Unfortunately, in most middle income countries, with the exception of few, some most institutions of higher learning rely on donations for computers. While not being guilt of looking a gift horse in the mouth - most donated computers will be obsolete. The interviewed IT regional technicians reiterated that it is not just a question of having computers and equipment - adding that these should be state of the art gadgets. They pointed out that the quality of equipment affects activities such as uploading and downloading of information as well as real time internet access - activities which are pivotal in Third Generation delivery.

\subsubsection{Setting up of infrastructure}

Any ODL institution needs to set up infrastructure for effective Third Generation delivery approach. Where the ODL university intends to use VSAT dissemination, there is need for a broadcasting centre and its requisite equipment at its head quarters. In addition, it requires infrastructure at its regional and district centres where students could converge to access learning disseminated through VSAT. In instances where the computer is the mode of delivery, there is need for well equipped computer laboratories at the regional and district centres. Murali (2012) underscores the need for ICT infrastructure in ODL systems. The infrastructure include the network infrastructure, the computing infrastructure, the system and application software, the Internet Service Provider (IPS), the bandwidth, the policy framework and the security structure. Establishing these infrastructures calls for substantial financial injection. Yet as observed by the World Bank (2010), most African 
countries' basic ICTs infrastructures are inadequate; this is as a result of lack of electricity to power the ICTs materials, poor telecommunication facilities, and a poor postal system. Above all the lack of access to the needed infrastructures is due to insufficient funds. The inadequacy of infrastructure is an issue even in relatively well developed countries, e.g. in the Open Universities in India, the usage of ICT is only 25\% (Tiwari \& Tiwari, 2010).

\subsubsection{Training of Teaching and Support Staff}

Equipping ODL practitioners so that they become conversant with preparation of learning, teaching and assessing of students' work online is crucial to successful Third Generation delivery. While computers can be programmed to mark multiple choice tests, they will always be need to assess essay questions, research proposals, research reports, dissertations and theses. Lecturer should be able to mark assignments delivered to them online. During focus group discussions, the general feeling was that lecturers were deficient in computer skills to enable them to read and mark assignments. In instances where some students email their assignments for marking, lecturers first of all download the assignments and mark the hardcopies. This phenomenon was corroborated by the three regional IT technicians who concurred in separate interviews that indeed most academic staff members experienced problems with computers. In a related study in Ghana, Addah, Kpedu and Kwapong(2012) found out that the capacity of teachers and educators to manage e-learning programs stilled remained low. While some did not have adequate computer skills, others were averse to using e-learning platforms. Acknowledging the limitations of teachers in a computer-driven learning, Rapatan (2002) notes that teachers must aim to be literate in the new technologies and retrain themselves in pedagogy for them to understand how to make technology support conceptual formation and change in students. The level of expertise of the online faculty and the depth and quality of faculty training and professional development program are some of the factors that can have either positive or negative impact on ODL (Cooper, 2000). In-servicing lecturers and support staff in the use of computers is hindered by financial constraints.

\subsubsection{Uploading of Teaching/Learning Materials and other relevant materials}

Before information is availed to students online, it must be uploaded onto the server platform. This exercise requires people with expertise. The challenge though for ODL institutions in middle income countries is that they may be incapacitated financially to be able to attract personnel of the right qualifications to perform these duties, needless to state that this will impact negatively on service delivery.

\subsubsection{Payment to service providers}

Service providers provide institutions with megabytes in accordance with how much institutions are prepared to pay. This means that if institutions pay little amounts they have access to very few megabytes per second. There is a positive correlation between megabytes per second received and the server's processing this will in turn affect the number of people who can access the net as well as the speed of uploading and downloading information. More often than not, due to underfunding, institutions are not in a position to pay as much as they would have liked. During focus group discussions most participants raised concerns regarding difficulties they at times experienced when surfing the net. They complained of failing to attach documents onto their emails at times. In separate interviews when this was brought to the attention of regional IT technicians, they explained that such challenges were linked to the megabytes received per second.

\subsubsection{Servicing of Equipment}

The equipment needs to be serviced periodically and repaired in case of breakdowns. In most institutions in middle income countries, it is not uncommon to come across equipment lying idle due to lack of maintenance. Most institutions operate on shoe string budgets, making it difficult for them to service, maintain, replace and repair equipment. When equipment breaks down and is not repaired, service delivery is affected. The impact of equipment breaking down can be catastrophic in ODL delivery.

\subsection{Strategies that ODLinstitutions can employ to circumvent funding-related challenges}

Participants raised a number of strategies that they considered important and practicable if ODL institutions are to successful move into the Third Generation of service delivery. Strategies that were common in all the three focus groups are presented and discussed below.

\subsubsection{Forging partnerships with private sector}

Participants pointed out that institutions can enter into partnerships with the private sector. An example was cited of a partnership that was forged between the University of Zimbabwe and Mbada Diamonds. The mining giant agreed to invest into the University's Geology Department. Apart from injecting finance into infrastructure development, the mining giant offers scholarship for students pursuing degrees related to mining. 
For example, it was generally agreed that ZOU could pull a leaf from this example, and enter into partnership with IT giants who own the optic fibre which facilitates computer-driven teaching and learning. Such a partnership can be in form of unlimited megabytes at subsidized cost to the institution. In turn, the service provider can also enjoy tax rebates, as a gesture for the provider's social responsibility in assisting the institution to access bandwidth at reasonable charges.

\subsubsection{Equity in the distribution of funds to Universities by the Government}

Available figures on finance allocation by Governmentshow that ZOU is the least funded institution of higher learning, notwithstanding the fact that it is the largest university in the country in terms of enrolment figures. Most participants felt that the government should exercise equity in the allocation of funds. They reiterated that increased funding may go a long way towards setting up the infrastructure to meet the requirements of the Third Generation of delivery.

\subsubsection{Diversification of programmes offered by ODL institutions}

Participants suggested that instead of solely focusing on traditional degree programmes, the university must have a bouquet of short professional courses. ZOU is already running farming courses, equipping newly resettled farmers with modern farming skills. Participants felt that more could be done, focusing on other sectors of the economy. In most cases, such courses may be paid for by the company that will have requested for the service.

\subsubsection{Widening Student base through aggressive marketing and introduction of courses responsive to the market demand}

Focus group participants were of the view that there was need to widen the student base through aggressive marketing. They pointed out that some conventional universities were also doubling into ODL, hence the need for aggressive marketing and introduction of courses responsive to market demands. The participants challenged the university to use its competitive advantage - its presence at the regional and district level, to recruit more students. The argument was that an increased student population meant more revenue from fees paid.

\subsubsection{Engaging the alumni}

The general feeling was that engaging the alumni in the university's development plans, may go some way in addressing some of the university's finance related challenges. Examples were highlighted of the University's regions that had benefited financially from engaging the alumni. The importance of alumni in sourcing funds for their former institutions is underscored by Rubens (2011). Alumni members have the advantage that they could be dotted throughout the country and in the diaspora, others could be occupying positions of influence in both the public and private sectors, this makes it easier for them to harness resources for their former institutions. In Zimbabwe, there are several examples of schools and colleges that have benefited immensely from alumni. In our view, institutions require alumni support now more than ever before due to the harsh economic conditions currently being experienced in the country.

\subsubsection{Own optic fibre for higher learning institutions in a particular country}

The idea of universities pulling resources to have their own fibre was raised in two of the three focus groups. The idea emanated from the realization that even in conventional universities computer-mediated instruction was becoming dominant. In view of escalating service charges by those who own the optic fibre, participants felt that universities should seriously consider having their own optic fibre. While acknowledging that the initial financial outlay may be colossal, the general consensus was that cumulative benefits will be immense.

\section{Conclusion}

- Without adequate funding, the progression of ODL institutions to the Third Generation will remain but a pipe dream.

- ODL practitioners' awareness of the impact of funding on the progress towards the Third Generation delivery mode bodes well for health debate within the institution as it attempts to navigate its way towards the Third Generation of delivery.

- ODL practitioners' awareness of their limitations in computer-driven ODL practices may motivate them to invest in their own computer training courses instead of waiting for the institution to send them for further training in the use of computers and related equipment.

\section{Recommendations}

- The university should increase its revenue base by running short professional courses in all its faculties. 
- $\quad$ Fostering of partnership between the university and the private sector.

- The Government should come up with a policy on ODL. Such a policy may make it mandatory for the Government to increase funding for ODL to appreciable levels. At present. ZOU receives the lowest allocation of funds from the State, despite it being the largest University in Zimbabwe in terms of enrolment figures.

- Entering into partnership with other well established ODL institutions that are already using the Third Generation of delivery for the training of teaching staff.

- With the increasing use of computer-driven instruction even in conventional universities, universities should seriously consider pulling resources to have their own optic fibre, instead of relying on services providers whose sole motive is deriving maximum profits.

\section{References}

[1]. Addah, K., Kpedu, D. \&Kwapong, Olivia, A. T. F.(2012). Promoting E-Learning in Distance Education Programs in an African Country.www.intechopen.com/.../e-learning...distance.../promoting-e-learning... (accessed August 20, 2012).

[2]. Chimedza, R. N. (undated). The Zimbabwe Open University's Delivery Mode, in Mutambanengwe, B. K. Zimbabwe Open University-New Student's Orientation Handbook.

[3]. COL (2004). Distance education and open learning in Sub-Saharan Africa: Criteria and conditions for quality and critical success factors. http://www.col.org/SiteCollectionDocuments/04DEinSSA_CriteriaforQuality.pdf (accessed August 30, 2012).

[4]. Cooper, L. (2000). Online course, The Journal, 27(8), 86-92.

[5]. Gwisai, M. (2006). Labor and employment Laws in Zimbabwe; Labor Centre and Institute of Commercial Law, University of Zimbabwe, Harare.

[6]. Holmberg, B., (1998) Essential of Distance Education Fernuiversitat. ZIFF.

[7]. Howell, S. L. Williams, P. B. \& Lindsay, N. K. (2003). Thirty-two Trends Affecting Distance Education: An Informed Foundation for Strategic Planning. Online Journal of Distance Learning Administration, 6, (3).

[8]. Murali, A. M. R. (2008). ICT in Open Distance Learning: Issues and Challenges. http://wikieducator.org/images/4/49/A._Murali_M_Rao.pdf (accessed August 30, 2012).

[9]. Murali, A. M. R. (2009). 'Web-enabled User Support Services System in Distance Learning', Proceedings of International Conference on Information Sciences; Information Technology, Culture and Human (ICIS 2009), The ACM International Conference Proceeding, 1, ISBN 978-1-60558-710-3, Seoul, Korea, 86-90.

[10]. Passerini, K. \& Granger, M. J. (2000). A developmental Model for distance learning using the Internet, Computers \& Education, 34, $1-15$.

[11]. Rapatan, M. (2002). Synergizing technology with cognition and pedagogy: A framework for designing e-learning programs. Paper presented in the National Conference of the Philippine e-Learning Society. 1-2 August. Manila.

[12]. Robinson, B. (2008). 'Using distance education and ICT to improve access, equity and the quality in rural teachers' professional development in western China', International Review of Research in Open and Distance Learning, 9, (1).

[13]. Rubens, N. (2011). Alumni Network Analysis - Innovative Ecosystems Network. www.innovative-ecosystems.org/wpcontent/.../2011/educon.pdf (accessed September 13, 2012).

[14]. Tiwari, I. \& Tiwari, G. T. (2010). Impact of Information Technology on Open Learning in India, International Journal of Compu ter Science and Network Security, 10, (11), 80-84.

[15]. World Bank. (2010) Financing Higher Education in Africa. The World BankInternet: www.worldbank.org (accessed September 8, 2012). 